Supporting Information for

\title{
Size-Tunable Synthesis of Metallic Nanoparticles in A Continuous and Steady-Flow Reactor
}

Chunwei Wu and Taofang Zeng*

Department of Mechanical and Aerospace Engineering, North Carolina State University, Raleigh, North Carolina 27695-7910, USA

* To whom the corresponding should be addressed. Phone: (919) 515-5298, email: tzeng2@ncsu.edu

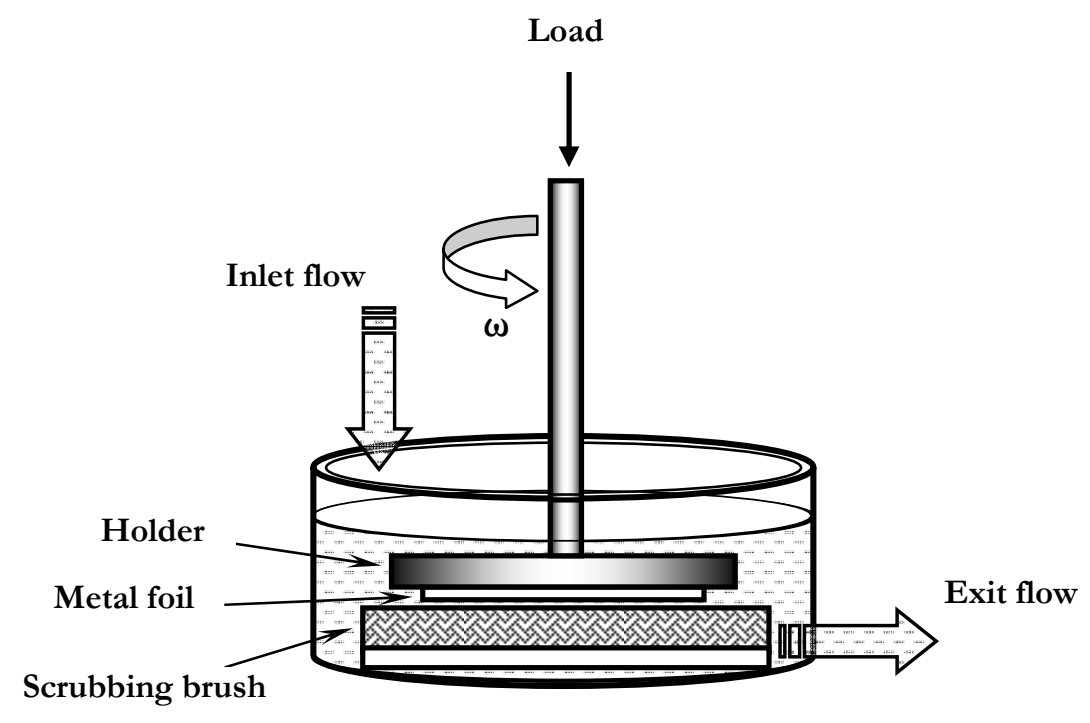

Figure S1. Scheme of the continuous and steady-flow reactor for synthesis of metallic nanoparticles. The designed reactor has a dimension (interior) of diameter $=8.5 \mathrm{~cm}$ and height $=7.5 \mathrm{~cm}$. 


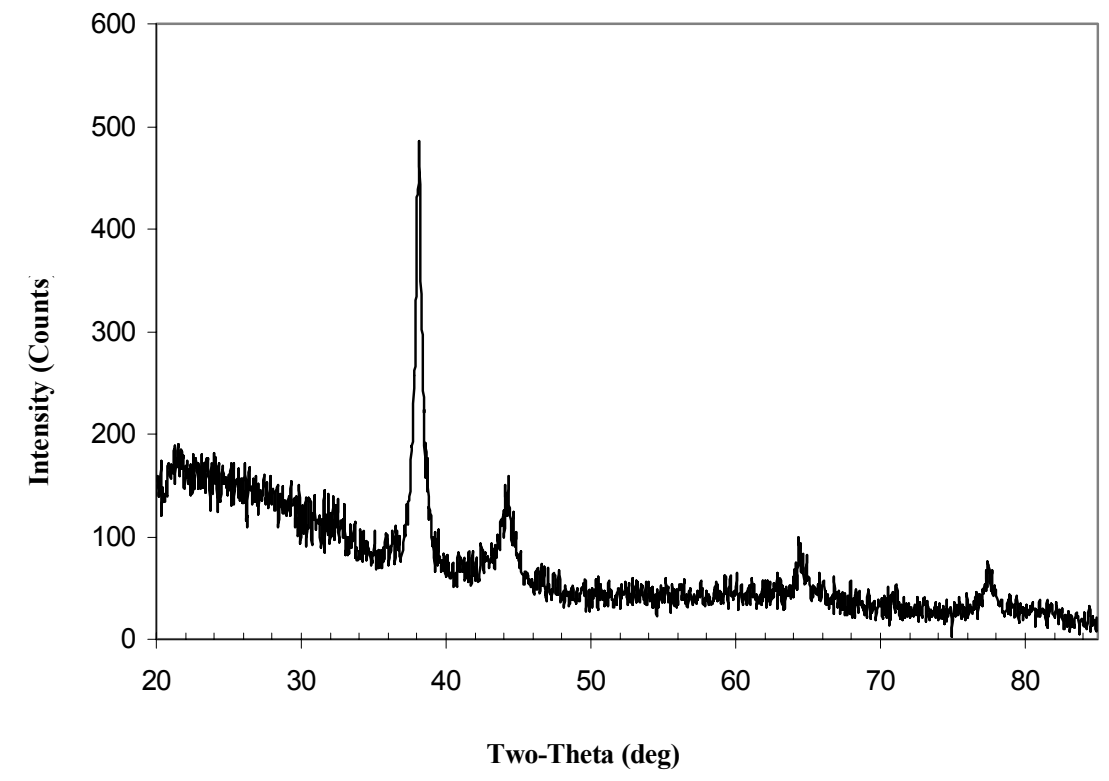

Figure S2. X-ray diffraction (XRD) pattern of silver nanoparticles synthesized by $\mathrm{Co}$ foil reduction in the continuous and steady-flow system. Diffraction peaks at $2 \theta=38.1,44.3,64.4$ and 77.4 degree correspond to the (111), (200), (220) and (311) crystalline planes of pure fcc Ag respectively. Ag nanoparticles reduced by $\mathrm{Fe}$ and $\mathrm{Ni}$ foil have similar XRD patterns as this one.

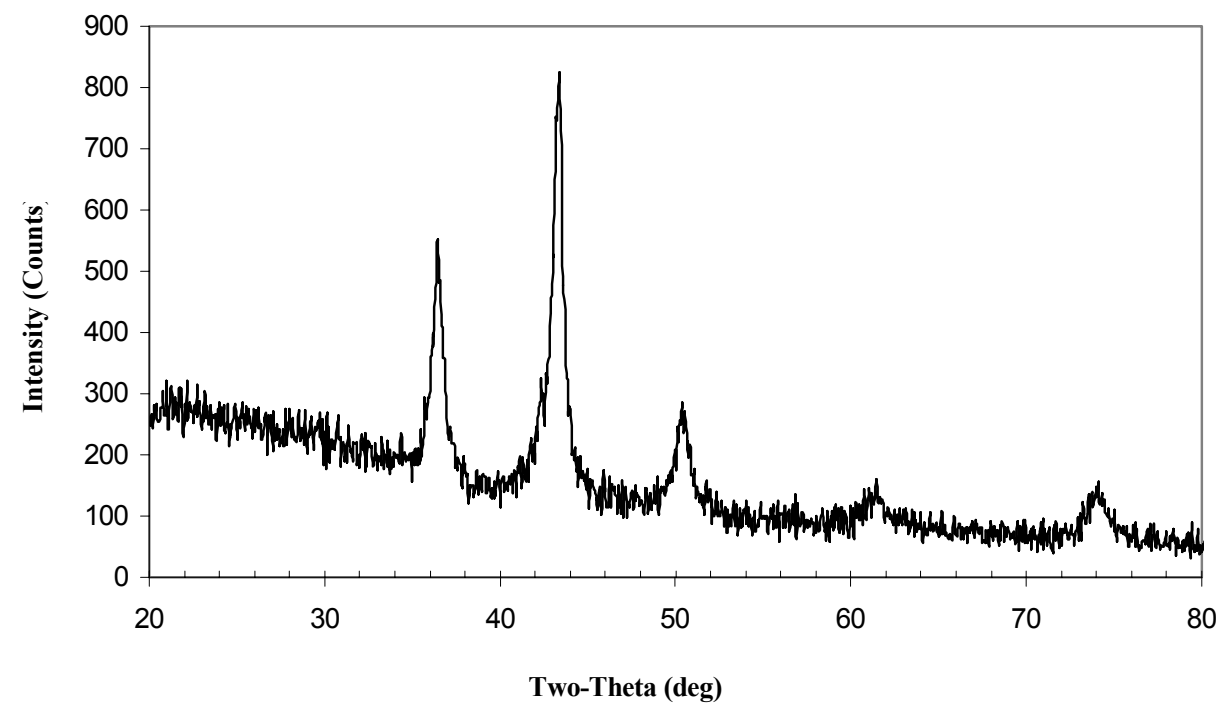

Figure S3. X-ray diffraction (XRD) pattern of partially oxidized copper nanoparticles synthesized in the continuous and steady-flow system. Diffraction peaks at $2 \theta=43.3,50.4$ and 74.1 degree correspond to (111), (200) and (220) crystalline planes of pure fcc $\mathrm{Cu}$ respectively; diffraction peaks at $2 \theta=36.4,42.3$ and 61.3 degree correspond to (111), (200) and (220) crystalline planes of $\mathrm{Cu}_{2} \mathrm{O}$ respectively. 